\title{
Use of Chitosan in Mosquito Repellent Finishing for Cotton Textiles
}

Bano $\mathbf{R}^{*}$

Mehran University of Engineering and Technology (MUET), Jamshoro, Sindh, Pakistan

*Corresponding author: Bano R, Mehran University of Engineering and Technology (MUET), Jamshoro, Sindh, Pakistan, Tel: +923000284867; E-mail: rafiashaikh_12@hotmail.com

Rec date: May 21, 2014, Acc date: Jul 25, 2014, Pub date: Aug 05, 2014

Copyright: (c) 2014 Bano R. This is an open-access article distributed under the terms of the Creative Commons Attribution License, which permits unrestricted use, distribution, and reproduction in any medium, provided the original author and source are credited.

\begin{abstract}
In present era of modernization in the textile field, we are going through new developments of technology. To ensure our security and safety from the hazards, we need to development the technology that should be reason for our protection. With regard to textiles, a mosquito repellent textile is one such textile product. It protects the human beings from the bite of mosquitoes and thereby promising safety from the diseases like malaria, dengue etc [1]. This abstract presents results of an investigation into mosquito finishing of cotton knitted fabric to improve water repellency. To impart this character in textiles we used commercial mosquito repellent finish that adheres with fabric by commercial binder. In next route of process we replaced commercial binder with natural binder chitosan. The main objective of this study was to investigate the possibility of using Chitosan as a binding agent for commercial repellent finish in order to increase the mosquito repellency and durability of cotton textiles. In result higher repellency was achieved when using chitosan as a binding agent. Additionally, resulted the increase in tensile strength of cotton fabric, thus increase in wash durability.
\end{abstract}

Keywords: Mosquito repellent; Textile field; Cotton fabric; Tensile strength; Chitosan

\section{Introduction}

Mosquito repellent textiles is one of the revolutionary ways to advance the textile field by providing the much needed features of driving away mosquitoes, especially in the tropical areas [3]. Because of global warming the distribution of mosquitoes has expanded from tropical regions to northern latitudes, and that leads to a spread in sources of viral infection from mosquitoes. Especially, the West Nile fever virus, which has infected many people around the world recently, has become a big issue [1]. The use of effective insect-repellents provides certain public health benefits. The applicable technologies in insect-repellent finishing are padding and microencapsulation [2]. Microencapsulated insect-resistant treatments are also used for textiles of natural protein fibers like wool and silk. Such finishes could provide long-term protection against mosquitoes [3]. Microencapsulation technology has enabled an increase in the durability of the desired effect in versatile textile finishing [4]. The microencapsulation finishes are not yet used extensively in the textile industry due to the prohibitive costs involved. More research is called for to produce more cost-effective mosquito repellent textiles that have a potential to become ultimately daily wear of people in the tropical areas, especially Asia [3]. This study was aimed to produce the mosquito repellent textiles with long lasting repellent efficacy as well as wash durability. This aim was achieved by pad-dry-bake application of commercial mosquito repellent finish Sanitized AM 23-24 with commercial binder (apprentan). In next phase of process we replaced the commercial binder with natural polymer binder chitosan. The padding solution for commercial binder (apprentan) prepared by recipe given by manufacturer but for natural polymer based binder the recipe was obtained through optimization of tensile strength. A natural polymer based chitosan binder found to be more durable then commercial binder (apprentan) with regards of mosquito repellency and wash durability of cotton fabric after testing.

\section{Experimental}

Cotton single jersey knitted fabric $\left(100 \mathrm{~g} / \mathrm{m}^{2}\right)$ was used and it was boiled-wash by solometic bleaching using $1 \%$ imerol PCLF, $1 \%$ of sodium hydroxide, $1.5 \%$ of hydrogen peroxide, $0.25 \%$ of stabilizer and $0.5 \%$ of sirrix $2 \mathrm{UD}$ all chemical and auxiliaries were supplied by Clariant Pakistan, the solution was prepared and the fabric was process on a Rapid laboratory HT dyeing machine for 30 minutes to achieve an adequate absorbency, i.e. 1 sec (AATCC 79).

The solution was prepared by following commercial recipe using 0.1\% Imerol PCL-F (Clariant Pakistan), $48.8 \mathrm{~g} / \mathrm{l}$ commercial mosquito repellent finish Sanitized AM 23-24 (Clariant Pakistan), commercial binder (Apprentan) (Clariant Pakistan), 4times of the concentration of Sanitized AM 23-24 and acetic acid (for $\mathrm{pH} 4-5$ ). This recipe was obtained through optimization for tensile behavior. But when we use chitosan in place of commercial binder (apprentan) the solution was prepared in $0.5 \mathrm{ml}$ acetic acid, 0.1 Imerol PCL-F, $48.8 \mathrm{~g} / \mathrm{l}$ commercial mosquito repellent finish Sanitized AM 23-24 and $1 \mathrm{~g} / \mathrm{l}$ chitosan (Marine chemicals, India). This recipe was also obtained through optimization for tensile behavior. In both recipes the fabric was padded in the solution on a Rapid laboratory horizontal padder with $80 \%$ wet pick-up followed by curing $\left(140^{\circ} \mathrm{C}\right.$ for $\left.75 \mathrm{sec}\right)$ on a Rapid laboratory stenter.

The treated and untreated fabrics were tested for mosquito repellency by following standard cage method, wash durability, tensile breaking strength (ASTM 5035 - 11), absorbency (AATCC 79), airpermeability (ASTM D 737 - 96), abrasion resistance (ASTM-D4966). 


\section{Results and Discussion}

Cotton textile was finished in order to make it functional towards mosquito repellency and simultaneously improving other properties of fabric. In $1^{\text {st }}$ phase fabric was treated by utilizing commercial mosquito repellent finish and binder through following commercial recipe. But when we replaced commercial binder with chitosan the recipe was obtained by optimization for tensile behavior. The recipe was optimized by varying process conditions such as concentration of chitosan, baking temperature and baking time, all of the samples were assessed by their tensile behavior. The results are given as follows:

\section{Effect of concentration of chitosan on tensile behavior}

It is evident from the given table that with the increase in concentration of Chitosan, there was rise in tensile strength of fabric. The best result obtained from all the experiments is at process conditions of $1 \mathrm{~g} / \mathrm{l}$ concentration of Chitosan, $\mathrm{pH}$ maintained was 5 and at temperature of $130^{\circ} \mathrm{C}$ for $45 \mathrm{sec}$.

\begin{tabular}{|l|l|}
\hline Conc: of chitosan $\mathbf{g} / \mathbf{l}$ & B-force $\mathbf{c N}$ \\
\hline 0.4 & 10700 \\
\hline 0.6 & 9907 \\
\hline 0.8 & 10350 \\
\hline 1 & 11010 \\
\hline
\end{tabular}

Table 1: Effect of concentration of chitosan (binder 2) on tensile behavior

\section{Effect of Baking temperature on tensile behavior}

It is clear from the given table that with the increase in temperature, there was rise in tensile strength of fabric. The best result obtained from all the experiments is at process conditions of temperature at $140^{\circ} \mathrm{C}$ for $60 \mathrm{sec}$ and $\mathrm{pH}$ maintained was 5 .

\begin{tabular}{|l|l|}
\hline Temperature $^{\circ} \mathbf{C}$ & B-force $\mathbf{C N}$ \\
\hline 130 & 9165 \\
\hline 140 & 10270 \\
\hline 150 & 8512 \\
\hline
\end{tabular}

Table 2: Effect of temperature on tensile behavior

\section{Effect of baking time on tensile behavior}

\begin{tabular}{|l|l|}
\hline Times (sec) & B-force (CN) \\
\hline 30 & 8119 \\
\hline 45 & 10090 \\
\hline 60 & 10660 \\
\hline 75 & 11330 \\
\hline
\end{tabular}

Table 3: Effect of time on tensile behavior

It is clear from the given table that with the increase in temperature, there was rise in tensile strength of fabric. The best result obtained from all the experiments is at process conditions of time for $75 \mathrm{sec}$ at temperature of $130^{\circ} \mathrm{C}$ and $\mathrm{pH}$ maintained was 5 .

\section{Chitosan verses Commercial binder}

\section{Mosquito repellency}

The repellent activity was evaluated by inserting a human hand and arm covered with the treated fabric into a test chamber $(18 \times 18 \times 18) \mathrm{cm}$, based on cage test. The covered arm was kept for five minutes in the test chamber containing approximately 200 blood-hungry mosquitoes. The number of insects landing was counted independently by observer. The same subject's uncovered arm and hand were also inserted as control.

The repellency was indirectly calculated from the percentage of insects landing on treated fabrics.

$\%$ Repellency $=100-($ MTF/MUF $\times 100)$

\begin{tabular}{|l|l|l|}
\hline Samples & \% Repellency \\
\hline \multirow{3}{*}{ Apprentan } & Before wash & 100 \\
\cline { 2 - 3 } & After wash & 0 \\
\hline \multirow{3}{*}{ Chitosan } & Before wash & 100 \\
\cline { 2 - 3 } & After wash & 100 \\
\hline
\end{tabular}

Table 4: Mosquito repellency

\section{Other properties}

The application of commercial mosquito finish in combination with commercial binder and chitosan gave different properties (Table 5).

\begin{tabular}{|l|l|l|l|l|}
\hline $\begin{array}{l}\text { S.No } \\
\cdot\end{array}$ & Property & $\begin{array}{l}\text { Untreated } \\
\text { fabric }\end{array}$ & apprentan & chitosan \\
\hline $\mathbf{1}$ & Breaking force (cN) & 10480 & 13180 & \\
\hline $\mathbf{2}$ & Elongation (\%) & 82 & 51 & 63 \\
\hline $\mathbf{3}$ & Absorbency (sec) & 2 & 2 & 1 \\
\hline $\mathbf{4}$ & Air-permeability (ml/sec) & $>400$ & $>400$ & $>400$ \\
\hline
\end{tabular}

Table 5: Breaking force, Elongation, Absorbency and Air-permeability of un- treated and treated cotton knitted fabric.

\section{Conclusion}

Pad-dry-bake application of commercial mosquito repellent finish Sanitized AM 23-24 with commercial binder and chitosan on cotton knitted fabric can be done to make the fabric mosquito repellent. This does not change the air-permeability of the fabric. Interestingly, the tensile strength is increased, which ultimately increases fabric durability. The finished fabric may be suitable for furniture fabrics, garments and military purpose.

\section{Acknowledgement}

We are thankful to Clariant chemical Pakistan for providing us Commercial mosquito repellent finish. 
Citation: Bano R (2014) Use of Chitosan in Mosquito Repellent Finishing for Cotton Textiles. J Textile Sci Eng 4: 162. doi: $10.4172 / 2165-8064.1000162$

Page 3 of 3

\section{References}

1. Malik T, Gadodiya K, Kumar A (2012) Mosquito repellent textiles. Institute of Technology and Science Indore.

2. Akbarzadeh A, Mokhtari J, Kolkoohi J, Sarli MA (2012) Imparting Insect Repellency to Nylon 6 Fibers by Means of a Novel MCT Reactive Dye. J Appl Polym Sci 126: 1097-1104.
3. Shirish Kumar GVN, Maheshwari R, Prabhu KH (2007) Recent developments of mosquito repellent textiles, ATA Journal for Asia on Textile \& Apparel.

4. Specosa MM, Garcíac JJ, Torneselloc J, Marinoa P, Della Vecchia MD, et al. (2010) Microencapsulated citronella oil for mosquito repellent finishing of cotton textiles, Trans R Soc Trop Med Hyg 104: 653-658. 